\title{
On the Role of Social Comparison Processes in Gamified Work Situations
}

\author{
Martin Huschens \\ University of Mainz \\ huschens@uni-mainz.de
}

\author{
Franz Rothlauf \\ University of Mainz \\ rothlauf@uni-mainz.de
}

\author{
Ricarda Rothe \\ University of Mainz \\ rrothe@students.uni-mainz.de
}

\begin{abstract}
Gamification, which can be defined as the use of game-design elements in the workplace, is a relatively new approach to foster work motivation. However, especially gamification elements based on rankings and leader boards create transparency among users, which allows for interpersonal social comparison. This paper gives a possible explanation why and how gamification based on a ranking influences motivation and perceived pressure by taking social comparison processes into account. To this end, we conducted a factorial survey $(N=156)$ to examine the effects of introducing a game-design element (public leader board) in the workplace. We found that the provision of a ranking increases motivation, perceived pressure and social comparison behavior. Importantly, we found that the motivational and pressuring effects can be largely explained by the extent of individual's social comparison behavior.
\end{abstract}

\section{Introduction}

A recent trend to increase workplace motivation is gamification, where game-design elements such as point systems, badges or leader boards are used in non-game contexts [1]. The aim is to create added value for a company and "to support users' overall value creation" [2, p. 25]. According to [3] one key principle that gamification should rely on to be effective is transparency. Indeed, most gamification elements create performance transparency [4] among users: Either progress or performance is presented individually to the user, e.g. by the use of progress bars or individual scoring systems or the system even provides transparency regarding the progress and performance of other users, e.g. by presenting leader boards or public badges. Regardless of which type of transparency creating element is implemented into an IS, there is one consequence of such performance transparency: it allows individuals to use this social comparison information to compare themselves with others inside or outside of an IS. As a consequence, enterprise gamification intensifies social comparison behavior.

Based on the assumption that intensified social comparison processes are a result of implementing gamification in the workplace, this paper studies whether social comparison behavior is a mediating variable that explains the effects of gamification usage. We hypothesize that the use of game-design elements not only directly shapes social comparison behavior, but that social comparison behavior itself is an important channel by which gamification unfolds motivational and pressuring effects on users.

To this end, we conducted a factorial survey in which subjects in the treatment group had to put themselves into a workplace situation in a call center in which a leader board was used to motivate staff in order to reach a certain performance goal. In contrast to that, the control group did not see a leader board. First, we found that the leader board in the treatment group is indeed a salient source of social comparison information and leads subjects to compare themselves with others significantly more than do those subjects in the control group. This suggests that the use of leader boards in gamified IS significantly shapes users' social comparison behavior. Further, we found strong evidence for the claim that gamification can be a "two-edged sword"1 [5, p. 865] in the workplace: its use leads to higher self-reported motivation and willingness to perform, however, at the same time, it increases perceived pressure.

Second, central to our study, we found that the effects of a leader board on motivation and pressure can be explained to a large proportion by the extent to which subjects compare themselves to others. First, we showed that one underlying cause of feeling under pressure in a gamified work situation is the stronger provision of

${ }^{1}$ [5] term social comparison information in the classroom as "two-edged sword" since such information might improve performance, however at the cost of detrimental effects on the academic self-concept. 
social comparison information that subsequently offers the possibility to compare oneself to others. Second, social comparison behavior also has strong explanatory power for motivational effects: Subjects feel motivated by comparing themselves to others, which explains the motivational effects of gamification to a large extent.

In section 2, we will provide the theoretical background of gamification, motivation theory, pressure, and social comparison theory in the context of gamification. In section 3, we will present our research model and hypothesis development. Next, we will describe the methodology of the factorial survey and present the results of the measure validation. In section 5, we will discuss the results and examine the role of social comparison behavior using mediated regression models. We will conclude with the managerial and research implications of our results and we will discuss the limitations of our study.

\section{Theoretical Background \& Literature Review}

\subsection{Gamification}

In line with the literature, we define gamification as the implementation of game-design elements into services in non-game contexts in order to support users' overall value creation, to reach a certain outcome, or to cause a behavior change $[1,2,3,6]$. There are two types of gamification: content and structural gamification [3] $]^{2}$. In content gamification, contents are altered to create a game-like experience, e.g. by adding story elements or transforming content into simulation games. Structural gamification adds game-design elements but does not change the task itself. The use of structural gamification by introducing single or combined game-design elements is more common in the workplace since a task or job itself can often not be easily turned into a game.

The literature further distinguishes between game dynamics and game mechanics [8]. Game mechanics are specific game-design components that can also be used in a non-game context. Common examples are point systems, badges, or leader boards (so called PBL-systems). In fact, those mechanics are just the visible instantiations of deeper underlying processes that generate players' engagement and drive the game action forward [6]. Competition, feedback or cooperation are examples of these internal processes created by the game mechanics, and are called game dynamics.

\footnotetext{
${ }^{2}$ Although [3] refer to this distinction in the domain of gamified e-learning systems, we hold this approach to be also very useful in other domains. [7] refer to this distinction as "gamifying content" vs. "gamifying method".
}

In general, there is one principle most gamification applications have in common: transparency [3, 4]. Indeed, many game mechanics make some user interaction, progress or performance standard visible to the user himself and/or to other users. Thus, performance transparency is an inherent part of most game-like experiences, especially if game mechanics are used that rely on the competitive drive of users (such as PBL-systems).

\subsection{Motivation}

Motivation is usually defined as an internal process that gives behavior its energy and direction [9]. Energy is the strength and persistence of the behavior in question. Direction gives behavior a specific purpose. Such being the case, motivation has an energizing function leading to higher performance, task perseverance, and attention [9].

According to the self-determination theory (SDT), motivation has three antecedents that are basic human needs: competence, autonomy and relatedness [9]. The feeling of competence can be described as a quest to control the outcome of a task and experience mastery. Autonomy refers to the feeling of being in control over the actions and outcomes and not being externally directed. Finally, relatedness is the universal need of humans to interact with and to be connected to others. According to the theory, if these three basic feelings are satisfied, they yield enhanced self-motivation [9].

Gamification elements may affect these needs of competence, autonomy and relatedness and thus lead to motivation: avatars, teams and group tasks influence the feelings of relatedness [10]; badges and leader boards relying on point systems can strengthen a feeling of competence since they provide immediate feedback [10]. If properly designed, gamification also gives users a feeling of autonomy rather than a feeling of being controlled $[6,10]$.

Additionally, an inherent feature of games and gamification is the provision of goals. Whether it is to be the first on the leader board or to gather as many badges as possible, gamification makes goals more salient. [11] claim that motivation is facilitated by such conscious goal-setting. Further they argue that goals have two effects on task performance. First, they have a directive function as they direct attention and effort towards goal-relevant activities. Goals give actions an object or aim. Second, goals have an energizing function and serve as motivational inducement [11].

The literature on the motivational effects of gamification is manifold: Most studies report positive effects on reported positive effects on engagement, 
motivation, learning gains and intrinsic motivation (for a recent overview see [12]). With regard to leader boards [13] showed that they are important sources for individual goal-setting and a useful tool to motivate participants to show higher performance levels in a brainstorming task. Also [14] found that leader boards act as progress indicators and immediate feedback, guiding and enhancing user performance on an image tagging platform. However, the leader board did not positively influence intrinsic motivation. In contrast, [15] found detrimental effects of providing students with a leader board and badges in an educational setting - motivation, school performance, and satisfaction dropped.

Comprehensive studies on the specific effects of gamification in workplace settings are rare. However, there is some work examining the effects of competition inducing techniques in a workplace environment without putting it in the context of gamification. For example, revealing workers' relative position on a leader board, which provides a relative performance feedback to employees, has been found to increase productivity and leads to significant performance gains (e.g., [16]). [17] also studied the negative outcomes of leader boards at the team level, and found that competition is positively related to team conflict, but negatively related to psychological safety.

\subsection{Perceived Pressure}

Perceived pressure is commonly defined as the perceived presence of situational incentives for optimal, maximal, or superior performance - often provided in the form of competition [18]. In pressuring situations, users might feel they need to show constantly higher performance, exceeding performance standards. Perceived pressure is different from the active pressure-exerting behavior of peers, colleagues or supervisors, for example based on (gamified) performance feedback. Indeed, perceived pressure is rather an inherent passive feeling that users experience as a reaction to a (gamified) working situation.

According to the SDT-theory, perceived pressure can be evoked by a lack of perceived autonomy in a task [19]. If a gamification technique is perceived as being controlling by a user, stress states are more likely to occur. For example, certain game-design elements such as leader boards can be perceived as a form of external evaluation and an external perceived locus of control [9].

While these negative effects of pressure are well known in the field of social psychology, the literature on gamification "has often emphasized the positive side of gamification" ([20], p. 235). Although in many studies, researchers have been unable to detect significant positive effects of the use of gamification, only a few studies specifically looked into the negative effects of gamification. The paper of [21] is to our knowledge the only study that examined pressure as an outcome variable. They found non-significant evidence that gamification by points, badges, and feedback leads to increased feelings of situational pressure. [14] posed the question whether specific game-design elements like leader boards harm intrinsic motivation since users might perceive points, levels and leader boards as controlling and pressuring. However, they did not find any significant negative effects.

\subsection{Social Comparison Behavior}

Social comparison has been a vital research area for decades. Social comparison behavior is a process in which human beings set information on social entities (including oneself) in relation to other social entities [22]. The social comparison theory builds (among others) upon two fundamental assumptions: First, that humans have an inherent desire to compare themselves with others and relate their own features (abilities and opinions) to those of relevant peers; second, that if subjects experience a discrepancy between themselves and their comparison targets, they tend to perform actions to minimize this difference. Specifically, with regard to abilities, experiencing inferiority leads to a basic drive upwards towards higher performance levels [23].

A large body of research in the domain of social comparison has focused on the consequences of social comparison processes. One important effect is the urge to reduce the discrepancy to comparison targets. A person's endeavor "to reduce discrepancies interacts with the unidirectional push to do better and better" [23, p. 124] and generates "competitive behavior to protect one's superiority" [23, p. 126]. As a result, competitive behavior patterns are likely manifestations of social comparison [24].

Although not directly addressed in social comparison literature, another research stream examined the effects of competitive behavior which is, following [23], a common consequence of social comparison. Early contributions by [25] found a positive influence of competition on performance, especially on tasks with low complexity. However, competition does also have its downsides, which have been extensively studied in the educational domain: In comparison to cooperative goal structures, subjects can feel like they are under pressure, they can exhibit higher anxiety levels and experience lower self-esteem 
[26]. These insights show that social comparison behavior might have important explanatory power for the motivational and pressuring effects of leader boards.

Despite the fact that many studies on the effects of gamification rely on the theory of social comparison (e.g. [27]), study the moderating role of social comparison orientations [4] in the use of gamification techniques, or examine the importance of social influences (subjective norms, social recognition, reciprocal benefits) for gamification adoption [28], to our knowledge only the study by [15] considers social comparison behavior as an outcome variable of the application of game-design elements - however the authors find non-significant results. Furthermore, no studies as of yet have examined social comparison processes as a channel by which gamification unfolds its effects.

\section{Research Model and Hypotheses}

We investigated the role of social comparison behavior in gamified work situations to provide an explanation why and how gamification with leader boards unfolds its effects. We assumed that social comparison behavior is not only an important outcome of the application of gamification but also an important channel for motivational and pressuring effects. Following [3], we view a leader board, which a common instantiation of gamification, as a feature of IS that creates and increases transparency among users. As a consequence, competitive behavior patterns are more likely when game-design elements are used, and this, in turn, has motivational and pressuring effects on the participants. Figure 1 shows our research model.

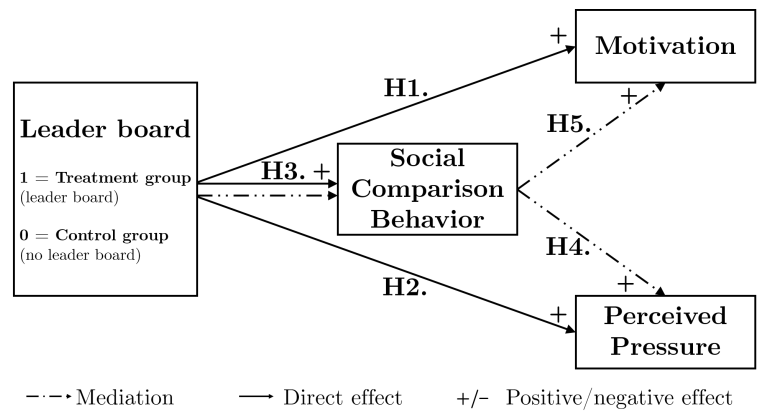

Figure 1. Research Model

First, we assumed that the leader board has a direct and positive effect on motivation due to increased performance transparency. Following the social comparison and goal-setting theories, gamification leads to higher motivational states as it enables comparison with others and is an important source to derive individual performance goals. Similarly, the social comparison theory postulates that in the case of upward comparison, social comparison information leads to "a basic drive upwards" [23] to reduce the discrepancy between an individual and their relevant peers. This leads to our first hypothesis:

H1. Applying leader boards in gamified IS increases motivation.

Second, we hypothesized that individuals perceive a higher level of pressure in such gamified work situations. [18] found that perceived pressure highly depends on the presence of comparative co-actors: individuals can be made aware of their lack of skill, status, or position relative to others [29]. In gamified IS, the presence of co-actors (here: colleagues) is a result of the application of game-design elements which make both personal performance and the performance of others visible to all users of the IS. This leads to hypothesis 2 :

H2. Applying leader boards in gamified IS increases perceived pressure.

The role of the outcome social comparison behavior was at the core of our study. We assumed that at the core - gamification techniques like leader boards represent social comparison information. Subjects use this information to compare themselves to peers. Consequently, such gamification techniques provide social standards that subjects tend to compare themselves to in order to build an elaborate self-appraisal [23]. Thus, we assumed that the use of a leader board, which allows for personalized comparison to peers on relevant performance dimensions, increases social comparison behavior among colleagues.

H3. Applying leader boards in gamified IS increases social comparison behavior.

Most importantly, we wanted to better understand the role of social comparison behavior in order to explain how gamification (e.g. by leader boards) unfolds its effects. We assumed that the effect of a leader board on perceived pressure and motivation can be explained to a large proportion by the strength of an individual's social comparison behavior. Concerning perceived pressure, we assumed that the effects are mainly driven by individual's social comparison concerns: Pressurizing stress states are caused by the opportunity to compare oneself to others which is delivered by the gamified IS. Hence, we hypothesized the following:

H4. The effect of leader boards in gamified IS on perceived pressure is mediated by individuals' social comparison behavior. 
In the case of motivating effects, we followed [25] and postulated a competition-performance relation as such: By creating a situation in which social comparison information is very salient, a gamification technique like a leader board increases competitive behavior patterns, which consequently leads to higher motivational states.

H5. The effect of leader boards in gamified IS on motivation is mediated by individuals' social comparison behavior.

\section{Research Methodology}

\subsection{Factorial Survey}

To test our hypotheses, we applied a psychological measurement by conducting a factorial survey (also called vignette study) [30]. Within factorial surveys, a hypothetical situation (vignette) is used as a stimulus, which is provided to the subjects before they answer a questionnaire. To make sure that subjects were blind to the condition, we used a between-subject design in which every subject was presented with a single vignette. Thus, we avoided subjects' mental overload, which can happen due to vignette length; we prevented sequence effects; and we controlled for response patterns that were guided by social desirability concerns or sponsorship effects. The participants were randomly assigned to either the treatment group or control group.

At the beginning of the survey all participants were asked to imagine that they were a call center agent. We then varied the performance feedback across the experimental groups: Subjects in the control group only received general feedback and a (team) performance goal. In contrast, the members of the treatment group saw a version of the situation including the game mechanic of a leader board. The public and personalized leader board provided information about the total number of phone calls each call center agent made. We chose the game-design element of a leader board because (1) leader boards are widely used in gamified IS and are of practical relevance; (2) leader boards are easy to implement and self-explanatory both in practice and for the purpose of our study; and (3) it is likely that the effects on social comparison behavior, motivation and perceived pressure are maximized since personalized leader boards based on a point system present the most elaborate social standard allowing for interpersonal comparison on a cardinal scale. In a final step, all participants had to answer the same questionnaire in order to measure the effect of the different vignettes on the outcome variables.

To make sure that the priming was successful, subjects had to recall the priming situation (vignette situation) after answering a few questions of the questionnaire. If the subjects were unable to answer these questions correctly, we repeated the priming by presenting the vignette once again. We used the following survey introduction for all participants:

Vignette (introduction): Please imagine the following situation: Your name is Thomas Nagel and you are working as a call center agent. Your job is to gather data for market research in the food industry. You are working together in an open space office with 34 other call center agents. There is a performance feedback feature in your intranet that tracks the interview count of all agents. It is expected that all 35 call center agents together reach 5,000 phone calls per week. This is what you see on your intranet:

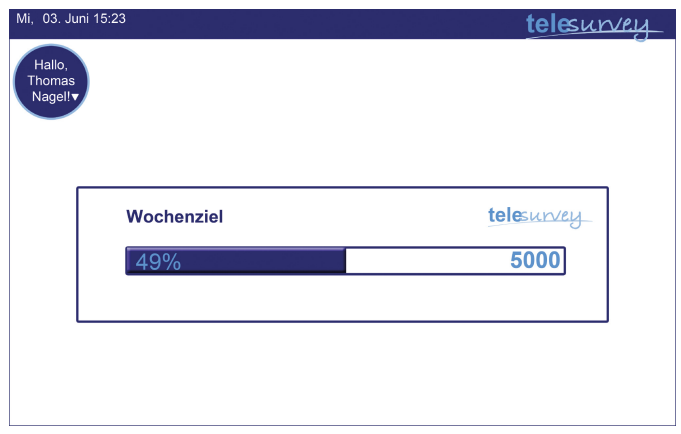

Figure 2. Vignette - general performance (team) goal seen in the introduction

After this introduction, we used two different vignettes for the treatment and control group, respectively:

Control Group: The performance goal of 5,000 interviews has not been met for several weeks. Hence, you and your colleagues were asked to put in more effort into reaching the goal. Your payment does not depend on your individual performance. ${ }^{3}$

In addition to that the treatment group received the following vignette:

Treatment Group: To reach the performance goal more frequently, the performance feedback feature in your intranet was updated. In addition to the overall performance goal of all call center agents, there is also a weekly public leader board. Your payment does not

\footnotetext{
${ }^{3}$ We excluded any monetary aspect of tournaments and rankings in order to first, make a distinction to a related strand of research in the field of economics that deals with the design of optimal labor contracts and tournament incentive (for an early contribution see [31]), and second, to focus on the consequences of social comparison processes and the pursuit of social status in the absence of monetary incentives. This allowed us to capture the non-pecuniary motivational and pressuring effects of gamification.
} 
depend on your individual performance and/or ranking position. This is the new screen you see in the intranet:

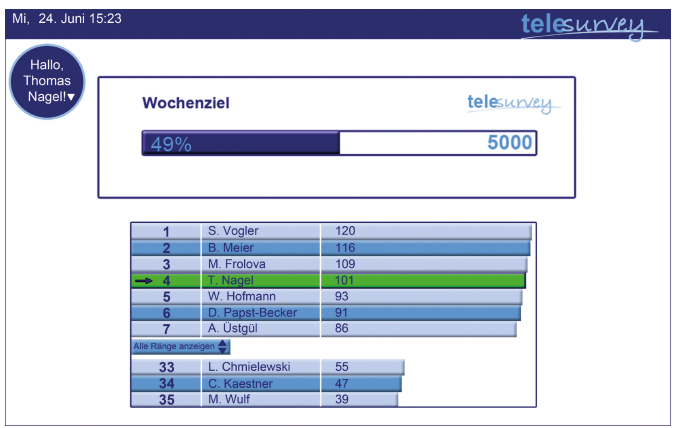

Figure 3. Vignette - public leader board for the treatment group

In the treatment group, employees were ranked high at the $4^{\text {th }}$ position (Figure 3 ), which is within the best $12 \%$ of all 35 employees. This was motivated by [24], and [29], who found that ranking subjects close to a relevant standard (top or bottom of the leader board) increases motivation and social comparison behavior. Furthermore, we refrained from placing subjects at the bottom of the leader board in order to avoid artificially high pressuring effects as a reaction to obvious inferiority and negative feedback [29].

The subsequent questionnaire included items from well-tested measurement instruments (see Table 2). For each item, we used a 7-point Likert scale anchored at $1=$ "strongly disagree" and $7=$ "strongly agree".

\subsection{Measure Development and Validation}

To confirm the reliability and validity of our measurement instrument, we performed a confirmatory factor analysis (CFA) in order to test the hypothesized underlying factor model.

The CFA proved an acceptable model fit $(C F I=.922, N N F I=.902$, RMSEA $=.089$, $S R M R=0.087, \chi^{2} / d f=2.234$ ). For construct validity, we examined both convergent and discriminant validity. Convergent validity was tested by examining the factor loadings. Table 2 shows that all items loaded very high on their respective factor as all factor loadings were greater than the recommended cutoff of .60 [32] and were statistically significant at the $1 \%$-level [32]. The inter-item correlations for all factors were also adequately high (social comparison behavior: .658, perceived pressure: .671 , motivation: .613) which indicates that the items measuring the same underlying construct are related. Since the average variance extracted (AVE) for all factors was also above .50 [33], there is strong support that convergent validity of the measurement instrument was adequate.
Additionally, we found strong support for discriminant validity since every item loaded higher on its own construct than on any other construct. The square root of the average variance extracted (AVE) should exceed all correlations between that factor and any other factor in the study [33]. Table 1 shows that, for all cases, the correlation between two constructs (off diagonal values) were lower than the square root of AVE (diagonal elements). This indicates that the measurement model discriminated adequately between the factors.

Table 1. Measure Validation - Discriminant Validity

\begin{tabular}{lccc}
\hline & SC & PP & MOT \\
\hline SC & $\mathbf{. 8 8 2}(.907)$ & & \\
PP & .216 & $\mathbf{. 8 6 5}(.890)$ & \\
MOT & .540 & .188 & $\mathbf{. 9 0 2}(\mathbf{. 8 6 1})$ \\
\hline
\end{tabular}

Notes: Diagonal elements are the square root of AVE. Off-diagonal elements are the inter-construct correlations. The Composite Reliability (CR) is provided in parentheses.

To assess the reliability of our measurement model and to ensure that all factors showed satisfactory levels of internal consistency, we examined the composite reliability of all factors. All values of the composite reliability (CR, see the diagonal elements of Table 1 in parentheses) support the reliability of our measurement instrument, since they were above the cutoff value of .80 [34]. In conclusion, we can assume that our measurement model captures the variables of interest both valid and reliable.

\subsection{Data Collection}

To empirically evaluate our research model, we posted a call on the news board of a large German university and promised a raffle of four $15 €$ gift certificates for the participants. The sample size was 156 participants, 78 male and 78 female. $96(61 \%)$ of the subjects were between 20 and 29 years old. The age groups 30-39, 40-49 and 50-59 were almost equally sized with $17-19$ subjects. 131 participants had an educational achievement of A-levels or a university degree. The largest groups were students (71) and employees (58). 83 (73) participants were allocated to the treatment group (control group).

Table 2 shows the descriptives per questionnaire item and the average composite score for the outcomes. For all items, the scores in the treatment group (TG) exceeded those of the control group (CG). This hints to a direct treatment effect of the gamified vignette. 
Table 2. Measure Validation (Factor Loadings) and Descriptives

\begin{tabular}{|c|c|c|c|c|}
\hline \multicolumn{2}{|l|}{ Item } & Std. Loading & Mean CG (SD) & Mean TG (SD \\
\hline \multicolumn{3}{|c|}{ Social Comparison Behavior $(\mathbf{S C})^{\mathbf{d}, \mathbf{e}}\left(\right.$ Source: SCOS $^{\mathrm{a}},[35]$ and WPI $\left.{ }^{\mathrm{b}},[36]\right)$} & $4.14(1.55)$ & $4.94(1.31)$ \\
\hline SC1 & For me, success means to be better than others. & $.729^{* * * *}$ & $3.99(1.84)$ & $4.88(1.84)$ \\
\hline $\mathrm{SC} 2$ & I take into account how well I perform in comparison to my colleagues. & $.831^{* * * *}$ & $4.12(1.75)$ & $4.89(1.60)$ \\
\hline $\mathrm{SC} 3$ & I want to be better than my colleagues. & $.894^{* * *}$ & $4.29(1.90)$ & $5.18(1.61)$ \\
\hline $\mathrm{SC} 4$ & I judge my performance in comparison to my colleagues. & $.752^{* * *}$ & $4.34(1.65)$ & $5.00(1.55)$ \\
\hline SC5 & It is important to me to perform better than my colleagues. & $.856^{* * *}$ & $3.97(1.65)$ & $4.75(1.67)$ \\
\hline \multicolumn{3}{|c|}{ Perceived Pressure (PP) ${ }^{\mathbf{d}, \mathbf{e}}$ (Source: IMI $^{\mathrm{c}}$ - Tension/Pressure-Scale, [9]) } & $4.56(1.55)$ & $5.17(1.47)$ \\
\hline PP1 & The performance target makes me feel nervous. & $.743^{* * *}$ & $4.49(1.64)$ & $4.83(1.70)$ \\
\hline PP2 & I feel put under pressure at work. & $.847^{* * * *}$ & $4.68(1.79)$ & $5.49(1.52)$ \\
\hline PP3 & I feel put under pressure by the performance feedback. & $.864^{* * * *}$ & $4.51(1.86)$ & $5.19(1.76)$ \\
\hline \multicolumn{3}{|c|}{ Motivation (MOT) ${ }^{\mathbf{d}, \mathbf{e}}$ (Source: IMI ${ }^{\mathrm{c}}$ - Interest/Enjoyment- and Effort-Scale, [9]) } & $4.28(1.39)$ & $5.01(1.16)$ \\
\hline MOT1 & I feel motivated by the performance feedback. & $.699^{* * * *}$ & $3.77(1.63)$ & $4.55(1.73)$ \\
\hline MOT2 & The performance feedback stimulates me. & $.753^{* * *}$ & $4.29(1.64)$ & $5.00(1.54)$ \\
\hline MOT3 & The performance feedback is an incentive for me. & $.882^{* * *}$ & $4.19(1.65)$ & $4.72(1.59)$ \\
\hline MOT4 & I put a lot of effort in reaching the performance goal. & $.676^{* * *}$ & $4.74(1.62)$ & $5.64(1.20)$ \\
\hline MOT5 & In response to the performance feedback I show more effort. & $.782^{* * *}$ & $4.44(1.47)$ & $5.16(1.43)$ \\
\hline
\end{tabular}

Notes: ${ }^{\mathrm{a}} \mathrm{SCOS}=$ Social Comparison Orientation Scale, ${ }^{\mathrm{b}} \mathrm{WPI}=$ Work Preference Index, ${ }^{\mathrm{c}}$ IMI $=$ Intrinsic Motivation Inventory

${ }^{\mathrm{d}}$ Average Composite Score of Factor Items; ${ }^{\mathrm{e}} \mathrm{CG}=$ Control Group (N=73), $\mathrm{TG}=$ Treatment Group (N=83)

****, indicate a significant $\mathrm{p}$-value at $\mathrm{p}<0.01$.

\section{Results}

\subsection{Direct Treatment Effects}

We examined whether there were statistically significant differences between the treatment group and control group. As our data is non-normally distributed ${ }^{4}$, we applied Mann-Whitney-U tests to test for median differences. The results are displayed in Table 3.

We found strong empirical support for a treatment effect of the gamified situation using a leader board. $\mathrm{H} 1$ and $\mathrm{H} 2$ postulated that the use of a leader board increases motivation and perceived pressure. We were able to accept both hypotheses: In the case of perceived pressure, individuals in the treatment group reported statistically significantly higher scores than individuals

\footnotetext{
${ }^{4}$ The QQ-plots indicated a significant deviation from a normal distribution for all outcome variables. Subsequent Kolmogorov-Smirnof-tests confirmed that the underlying distributions of the test scores for social comparison behavior $\left(\mathrm{D}_{\mathrm{TG}}(83)=.962\right.$, p $\left.<.05 ; \mathrm{D}_{\mathrm{CG}}(73)=.882, \mathrm{p}<.05\right)$, perceived pressure $\left(\mathrm{D}_{\mathrm{TG}}(83)=.960\right.$ $\left.\mathrm{p}<.05 ; \mathrm{D}_{\mathrm{CG}}(73)=.949, \mathrm{p}<.05\right)$ and motivation $\left(\mathrm{D}_{\mathrm{TG}}(83)=.986\right.$, $\left.\mathrm{p}<.05 ; \mathrm{D}_{\mathrm{CG}}(73)=.937, \mathrm{p}<.05\right)$ in both the control group and the treatment group were all non-normal.
}

Table 3. Results of Mann-Whitney-U-Tests

\begin{tabular}{lccccc}
\multicolumn{6}{c}{ Median } \\
Outcome & $\mathrm{CG}^{\mathrm{a}}$ & $\mathrm{TG}^{\mathrm{a}}$ & $\mathrm{U}$ & $\mathrm{z}$ & $\mathrm{r}$ \\
\hline SC & 4.4 & 5.0 & 2156.5 & $-3.104^{* * *}$ & .248 \\
PP & 5.0 & 5.6 & 2278 & $-2.678^{* * *}$ & .238 \\
MOT & 4.6 & 5.0 & 2195 & $-2.970^{* * *}$ & .215 \\
\hline \multicolumn{5}{l}{ Notes: ${ }^{* * *}$, indicate a significant p-value at p $<0.01}$. \\
a CG = Control Group, TG = Treatment Group
\end{tabular}

in the control group $(U=2278, z=-2.678, p<$ .001). This is a very important insight into the effects of providing leader boards in the workplace: Even well-performing subjects (those ranked among the top $15 \%$ of all employees on the leader board) felt put under pressure by the leader board provided. This pressuring effect was of medium size $\left(r_{P P}=.238\right)$. However, we also found significant motivational effects. Putting individuals in a gamified work situation with a leader board accounts for a significant part of the variations in the motivation outcome variable $(U=2195$, $z=-2.970, p<.001)$. Again, the effect size was medium $\left(r_{M O T}=.215\right)$.

H3 predicted that gamification leads to increased social comparison behavior due to performance transparency. When we compared the treatment group and the control group, we found that the median of the treatment group ( $M d n=5.0)$ was higher than that of the control group ( $M d n=4.4$ ). This difference was statistically highly significant $(U=2156.5$, $z=-3.104, p<.001)$. The effect size can be labeled as medium $\left(r_{S C}=.248\right)$. These results account for the fact that the use of a leader board significantly facilitates social comparison behavior and competitive behavior patterns. In summary, this first analysis allows us to conclude that the treatment of applying gamification in the workplace leads to an increase in motivation, perceived pressure and social comparison behavior. 
Table 4. Regression Models - 3-step Mediator Analysis for Perceived Pressure and Motivation

\begin{tabular}{|c|c|c|c|c|c|c|c|c|}
\hline & \multicolumn{4}{|c|}{ Perceived Pressure } & \multicolumn{4}{|c|}{ Motivation } \\
\hline & Coef. & $\mathrm{F}$ & $\mathrm{R}^{2}$ & $\mathrm{Z}^{\mathrm{b}}$ & Coef. & $\mathrm{F}$ & $\mathrm{R}^{2}$ & $\mathrm{Z}^{\mathrm{b}}$ \\
\hline Model 1 ${ }^{\mathrm{a}}:$ IV $\rightarrow$ DV & & $6.376^{* *}$ & .033 & & & $12.8^{* * *}$ & .071 & \\
\hline$P P / M O T=\gamma_{1}+\gamma_{2} L B+\epsilon$ & & & & & & & & \\
\hline Leader Board (LB, $\left.\gamma_{2}\right)$ & $.611^{*}$ & & & & $.729^{* * *}$ & & & \\
\hline Model $2^{\mathrm{a}}:$ IV $\rightarrow$ MED & & $12.07^{* * *}$ & .067 & & & $12.07^{* * *}$ & .067 & \\
\hline$S C=\alpha_{1}+\alpha_{2} L B+\epsilon$ & & & & & & & & \\
\hline Leader Board $\left(\mathrm{LB}, \alpha_{2}\right)$ & $.797^{* * *}$ & & & & $.797^{* * *}$ & & & \\
\hline Model $3^{\mathrm{a}}:$ IV + MED $\rightarrow$ DV & & $7.322^{* * * *}$ & .075 & $2.139^{* *}$ & & $41.14^{* * *}$ & .341 & $3.167^{* * * *}$ \\
\hline$P P / M O T=\delta_{1}+\beta_{2} S C+\gamma_{3}^{\prime} L B+\epsilon$ & & & & & & & & \\
\hline Social Comparison Behavior (SC, $\left.\beta_{2}\right)$ & $.235^{* *}$ & & & & $.484^{* * *}$ & & & \\
\hline Leader Board (LB, $\left.\gamma_{3}^{\prime}\right)$ & $.424^{n . s .}$ & & & & $.344^{*}$ & & & \\
\hline
\end{tabular}

Notes: $\mathrm{N}=156 ;{ }^{* * *},{ }^{* *},{ }^{*}$ indicate a significant $\mathrm{p}$-value at $\mathrm{p}<0.01,0.05,0.10$ respectively.

a $=$ Regression Models are controlled for relevant covariates such as age, gender, income and educational achievement.

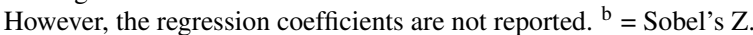

\subsection{Mediation Analysis}

To examine social comparison behavior as possible channel by which a leader board in the workplace unfolds its effects, we investigated a possible mediation by applying a 3 -step mediator analysis $[37$, see Table 4]. In particular, we tested the significance of the indirect effect of the independent variable (IV = leader board) on the dependent variables (DV = motivation or perceived pressure) through the mediator (MED = social comparison behavior). We assumed that the mediator variable social comparison behavior specifies how and why certain motivational and pressuring effects of leader boards occur.

$\mathrm{H} 4$ assumed that the effect of a leader board on perceived pressure is mediated by individuals' social comparison behavior. Mediation analysis confirmed this assumption. First, as already shown, the leader board had a positive and statistically significant effect on social comparison behavior (Model 2, $\alpha_{2}=.797^{* * *}$ ). Second, Model 1 suggests that the leader board also increased perceived pressure $\left(\gamma_{2}=.611^{*}\right)$. However, when the regression model was controlled for the influence of the mediator, this direct effect of the leader board became non-significant in the mediation model (Model 3, $\gamma_{3}^{\prime}=.424^{n . s .}$ ). These results indicate a perfect mediation. The mediation effect amounted to $.187\left(\alpha_{2} * \gamma_{3}^{\prime}\right)$ and, according to Sobel's $Z^{5}(Z=2.139$, $p<.05)$, was of significant size.

H5 assumed that increased social comparison behavior is also a possible explanation of the

${ }^{5}$ Sobel's $\mathrm{Z}$ assesses if the relationship between the independent variable (leader board, LB) and the dependent variable (perceived pressure, PP or motivation, MOT) is significantly lower when considering the mediator (social comparison behavior, SC) in the regression model. motivational effects of gamification. Our results confirmed a partial mediation effect: When modeling social comparison behavior as being a mediator in Model 3, the influence between the treatment condition applying a leader board and motivation $\left(\gamma_{2}=.729^{* * *}\right)$ became less significant and weaker $\left(\gamma_{3}^{\prime}=.344^{*}\right)$. The mediation effect was highly significant $\left(\alpha_{2} * \gamma_{3}^{\prime}=\right.$ $.386, Z=3.167, p<.01$ ), indicating that social comparison behavior - enabled by the possibility to compare their own performance to the performance of relevant peers - accounts for a significant part of the variations in the motivational states of participants.

To sum up the results, the strength of self-reported social comparison behavior has strong explanatory power for the effects of gamification using leader boards. First, there is strong evidence that the motivation-enhancing effects of social comparison behavior exist. We find that the leader board itself only indirectly leads to motivational outcomes - a channel by which these motivational effects are evoked is social comparison behavior. The game-design element of a public leader board acts as a relevant and effective social standard leading to stronger comparative behavior patterns and motivation, in comparison to a (team) goal.

Second, we found a full mediation effect for perceived pressure: When we controlled for social comparison behavior, there was no longer any significant direct effect of the leader board treatment on perceived pressure. We thus showed that stress states as a consequence of being presented on a leader board expressed by perceived pressure - can be explained by increased interpersonal comparisons (social comparison behavior). 


\section{Discussion \& Limitations}

We studied the functioning and effects of introducing a leader board into the workplace. We found that the use of gamification elements like leader boards increases motivation, social comparison behavior and perceived pressure. Thus, our results confirm that gamification in the workplace is "a two-edged sword" [5], with both negative and positive effects. When looking at the functioning of a prominent game mechanic (a leader board), we found that the influence of the leader board on motivation and perceived pressure is mediated by the subject's social comparison behavior. Since we argued that most gamification elements rely to a certain extent on providing social comparison information and creating performance transparency, our results are also relevant for other game mechanics such as badges, quests, or point systems.

Consequently, social planners in companies should not only carefully evaluate the possible use of gaming techniques in the workplace, but also consider that gamification affects social comparison behavior. Although the use of gamification in work environments increases motivation, it also leads to negative effects since it increases perceived pressure. Thus, social planners are faced with a trade-off between higher performance due to higher motivation, and negative effects due to higher perceived pressure. These effects can be explained to a large proportion by social comparison processes that are induced by gamification elements. In general, this leads to the conclusion that social comparison processes should be carefully managed within an organization in order to create motivational effects while at the same time avoiding overarching perceived pressure.

Our results may give guidance for future work. We found that an increase in social comparison is a relevant mechanism explaining the functioning of gamification. Consequently, considering social comparison processes can be helpful for explaining the diverse results of the effects of gamification across different studies. We recommend replicating certain gamification studies, while additionally taking into account the role of social comparison behavior as a mediator for certain outcomes. We believe that this would lead to a better understanding of the effects of gamification.

Another promising research direction is a deeper examination of the motivation construct. As of yet, it is still unclear whether the application of gamification techniques fosters intrinsic motivation or extrinsic motivation. From the business perspective it would be helpful to better understand how gamification creates motivation, and to know which game-design elements are linked to the different motivational effects. A deeper look into grounded motivation theories with regards to the antecedents of motivation (SDT theory: competence, autonomy, relatedness) and its relation to different game-design elements should be taken and empirically tested in a field-setting. A first paper addressing this issue was recently published by [10]. Overall, we believe that the psychological functioning of gamification is a promising area of future research.

Our study has some limitations. First, our data set contains only self-reported measures. Behavioral measures gathered in a field study would certainly be valuable in order to confirm our results. Furthermore, a vignette situation can never be fully realistic and is prone to individual misperceptions - especially for those (female) subjects who could not easily identify with the vignette character. Thus, the external validity of our study might be limited and controlled randomized field studies should be performed to back up our findings. Second, due to our research method (factorial survey), we were limited to presenting participants with only one possible ranking position (in our case: $4^{\text {th }}$ ). Additional field studies on the effects of gamification and different ranking positions are necessary to gain a better understanding on how the ranking position affects employees. This could deliver valuable insights into the psychological effects of relative performance information in IS on employees. Fourth, in order to confirm the claim that most gamification elements rely on performance transparency and subsequently foster social comparison processes, this study should be replicated with other game mechanics.

\section{References}

[1] S. Deterding, D. Dixon, R. Khaled, and L. Nacke, "From Game Design Elements to Gamefulness: Defining Gamification," in MindTrek '11 Proceedings of the 15th International Academic MindTrek Conference: Envisioning Future Media Environments, (Tampere, Finland), pp. 9-15, ACM, 2011.

[2] K. Huotari and J. Hamari, “A definition for gamification: anchoring gamification in the service marketing literature," Electronic Markets, vol. 27, no. 2017, pp. 21-31, 2017.

[3] K. M. Kapp, L. Blair, and R. Mesch, Gamification of Learning and Instruction Fieldbook: Ideas into Practice. San Francisco, CA: Wiley, 2014.

[4] E. S. Bernstein and S. X. Li, "Seeing Where You Stand: From Performance Feedback to Performance Transparency," in Academy of Management Proceedings, (Briarcliff Manor, NY), p. 14752, 2017.

[5] P. Dijkstra, H. Kuyper, G. V. D. Werf, A. P. Buunk, and Y. G. V. D. Zee, "Social Comparison in the Classroom: A Review," Review of Educational Research, vol. 78, no. 4, pp. 828-879, 2008.

[6] K. Werbach and D. Hunter, How Game Thinking Can 
Revolutionize Your Business. Philadelphia, PA: Wharton Digital Press, 2012.

[7] M. B. Armstrong and R. N. Landers, "Gamification of employee training and development," International Journal of Training and Development, vol. 22, no. 2, pp. 1-8, 2018.

[8] I. Blohm and J. M. Leimeister, "Gamification," Wirtschaftsinformatik, vol. 55, no. 4, pp. 275-278, 2013.

[9] R. M. Ryan and E. L. Deci, "Self-determination Theory and the Facilitation of Intrinsic Motivation, Social Development, and Well-Being.," The American Psychologist, vol. 55, no. 1, pp. 68-78, 2000.

[10] M. Sailer, J. U. Hense, S. K. Mayr, and H. Mandl, "How gamification motivates: An experimental study of the effects of specific game design elements on psychological need satisfaction," Computers in Human Behavior, vol. 69, pp. 371-380, 2017.

[11] E. Locke and G. P. Latham, "Motivation through conscious goal setting," Applied and Preventive Psychology, vol. 5, no. 2, pp. 117-124, 1996.

[12] D. Albertazzi, M. G. G. Ferreira, and F. A. Forcellini, "A Wide View on Gamification," Technology, Knowledge and Learning, vol. 2018, pp. 1-12, 2018.

[13] R. N. Landers, K. N. Bauer, and R. C. Callan, "Gamification of task performance with leaderboards: A goal setting experiment," Computers in Human Behavior, vol. 71, pp. 508-515, 2017.

[14] E. D. Mekler, F. Brühlmann, A. N. Tuch, and K. Opwis, "Towards understanding the effects of individual gamification elements on intrinsic motivation and performance," Computers in Human Behavior, vol. 71, pp. 525-534, 2017.

[15] M. D. Hanus and J. Fox, "Assessing the effects of gamification in the classroom: A longitudinal study on intrinsic motivation, social comparison, satisfaction, effort, and academic performance," Computers \& Education, vol. 80, pp. 152-161, 2015.

[16] J. Blanes i Vidal and M. Nossol, "Tournaments without prizes: evidence from personnel records," Management Science, vol. 57, no. 10, pp. 1721-1736, 2011.

[17] R. Brouwer, "When competition is the loser: The indirect effect of intra-team competition on team performance through task complexity, team conflict and psychological safety," in Proceedings of the 49th Annual Hawail International Conference on System Sciences, (Hawaii), pp. 1348-1357, IEEE, 2016.

[18] R. F. Baumeister and C. J. Showers, "A Review of Paradoxical Performance Effects: Choking Under Pressure in Sports and Mental Tests," European Journal of Social Psychology, vol. 16, no. 4, pp. 361-383, 1986.

[19] R. M. Ryan and E. L. Deci, "Self-regulation and the problem of human autonomy: Does psychology need choice, self-determination, and will?," Journal of Personality, vol. 74, no. 6, pp. 1557-1585, 2006.

[20] A. Shahri, M. Hosseini, K. Phalp, J. Taylor, and R. Ali, "Towards a Code of Ethics for Gamification at Enterprise," in 7th IFIP WG 8.1 Working Conference, PoEM 2014, (Manchester), pp. 235-245, Springer, 2014.

[21] L. Z. Pedro, A. M. Z. Lopes, B. G. Prates, J. Vassileva, and S. Isotani, "Does gamification work for boys and girls?" in Proceedings of the 30th Annual ACM Symposium on Applied Computing - SAC '15, (Salamanca, Spain), pp. 214-219, ACM, 2015.
[22] K. Corcoran, J. Crusius, and T. Mussweiler, "Social comparison - Motives, Standards and Mechanisms," in Theories in Social Psychology (D. Chadee, ed.), pp. 119-139, Oxford, UK: Wiley-Blackwell, 2011.

[23] L. Festinger, "A Theory of Social Comparison Processes," Human Relations, vol. 7, no. 2, pp. 117-140, 1954.

[24] S. M. Garcia, A. Tor, and T. M. Schiff, "The Psychology of Competition: A Social Comparison Perspective," Perspectives on Psychological Science, vol. 8, no. 6, pp. 634-650, 2013.

[25] I. C. Whittemore, "The influence of competition on performance: an experimental study," Journal of Abnormal Psychology and Social Psychology, vol. 19, pp. 236-254, 1925.

[26] D. W. Johnson and R. T. Johnson, "Instructional Goal Structure: Cooperative, Competitive, or Individualistic," Review of Educational Research, vol. 44, no. 2, pp. 213-240, 1974.

[27] K. R. Christy and J. Fox, "Leaderboards in a virtual classroom: A test of stereotype threat and social comparison explanations for women's math performance," Computers and Education, vol. 78, pp. 66-77, 2014.

[28] J. Hamari and J. Koivisto, "Working out for likes": An empirical study on social influence in exercise gamification," Computers in Human Behavior, vol. 50, pp. 333-347, 2015.

[29] S. M. Garcia, A. Tor, and R. Gonzalez, "Ranks and rivals: a theory of competition.," Personality \& social psychology bulletin, vol. 32, no. 7, pp. 970-82, 2006.

[30] P. H. Rossi, "Vignette Analysis: Uncovering the Normative Structure of Complex Judgments," in Qualitative and Quantitative Social Research: Papers in Honor of Paul F. Lazarsfeld (R. K. Merton, J. S. Coleman, and P. H. Rossi, eds.), pp. 176-186, London: Collier Macmillan Publishers, 1979.

[31] E. P. Lazear and S. Rosen, "Rank-Order Tournaments as Optimum Labor Contracts," Journal of Political Economy, vol. 89, no. 5, pp. 841-864, 1981.

[32] J. F. Hair, R. E. Anderson, R. L. Tatham, and W. C. Black, Multivariate Data Analysis. New York: Macmillan, 3rd ed., 1998.

[33] C. Fornell and D. F. Larcker, "Evaluating Structural Equation Models with Unobservable Variables and Measurement Error," Journal of Marketing Research, vol. 18 , no. 1, pp. 39-50, 1981.

[34] J. Nunnally and I. H. Bernstein, Psychometric Theory. New York, NY: McGraw-Hill, 1994.

[35] F. X. Gibbons and B. P. Buunk, "Individual differences in social comparison: Development of a scale of social comparison orientation.," vol. 76, no. 1, pp. 129-142, 1999.

[36] T. M. Amabile, K. G. Hill, B. a. Hennessey, and E. M. Tighe, "The Work Preference Inventory: assessing intrinsic and extrinsic motivational orientations.," Journal of Personality and Social Psychology, vol. 66, no. 5, pp. 950-967, 1994.

[37] R. M. Baron and D. A. Kenny, "The moderator-mediator variable distinction in social psychological research: conceptual, strategic, and statistical considerations.," Journal of personality and social psychology, vol. 51, no. 6, pp. 1173-1182, 1986. 